\title{
Veterans' Likelihood of Reporting Cardiovascular
} Disease

\author{
Ramon Hinojosa, $\mathrm{PhD}$
}

Objective: Cardiovascular disease (CVD) is the most common chronic health condition affecting Americans. One important group of Americans that health researchers have noted as key to understanding general population health and wellbeing are veterans of the US military. The healthy soldier effect has been used to explain the health benefits of military service during and for a period of time after service. The purpose of this study was to examine the prevalence of CVD in a national sample with specific attention paid to reported CVD across ages.

Methods: A total of 153,556 veteran and nonveteran respondents from the National Health Interview Survey were examined for the likelihood of reporting the type and number of cardiovascular conditions.

Results: Veterans report higher rates of certain CVD conditions and report a higher number of CVD conditions than nonveterans. Veterans also reported higher numbers of CVD conditions at younger ages (ages 25 to 70 years) than nonveteran counterparts. At older ages (ages 70 to 85+ years), nonveterans reported higher numbers of CVD conditions than veterans.

Discussion: Our findings are consistent with the studies that indicate a waning healthy soldier effect for young veterans potentially due to the unique circumstances of the current conflicts. ( $\mathrm{J}$ Am Board Fam Med 2019;32:50-57.)

Keywords: Cardiovascular Diseases, Military Personnel, Prevalence, Surveys and Questionnaires, Veterans

Cardiovascular disease (CVD) is the most common chronic health condition in the United States. Almost $30 \%$ of Americans suffer from at least 1 cardiovascular condition, and $50 \%$ of adults 60 years of age or older have 1 or more cardiovascular conditions. ${ }^{1}$ CVD is the leading cause of death for American men and women and contributes to $31 \%$ of all deaths in the United States each year. ${ }^{1}$ One important group that health researchers have noted as key to understanding general population health are veterans of the American military. ${ }^{2}$ There are approximately 21 million veterans, ${ }^{3}$ representing about $9 \%$ of the civilian noninstitutionalized adult population and approximately $7 \%$ of the total

\footnotetext{
This article was externally peer reviewed.

Submitted 15 May 2018; revised 30 August 2018; accepted 7 September 2018.

From Department of Sociology, University of Central Florida, Orlando (RH).

Funding: none.

Conflict of interest: none declared.

Corresponding author: Ramon Hinojosa, PhD, Department of Sociology, University of Central Florida, 4297 Andromeda Loop N., Orlando, FL 32816 (E-mail: Ramon.Hinojosa@ ucf.edu).
}

American population overall. ${ }^{2,4}$ In this article, "veteran" is defined as those who have ever served in the United States Armed Forces. Although selfreports of having ever served may not meet the strict legal criteria for being eligible for veteran affairs benefits, the definition is consistent with that used by the National Health Interview Survey (NHIS), the source of data for the current analysis. ${ }^{1}$

Military service has long been associated with both positive and negative health outcomes. ${ }^{6-8}$ Active-duty service members tend to be more physically fit and less likely to be overweight than sameaged nonmilitary civilians. ${ }^{9}$ This phenomenon is often referred to as the "healthy soldier effect" (HSE). ${ }^{9}$ The HSE is an adaptation of the healthy

\footnotetext{
${ }^{1}$ Veteran status is defined according to American legal code (38 U.S. Code $\$ 101)$ as military personnel that have "served in the active military, naval, or air service" and were "discharged or released therefrom under conditions other than dishonorable". 38 U.S. Code $\$ 101$ establishes the legal definition for Veteran as a means to determine eligibility for Veterans' Benefits 5. Veterans' Benefits., Public Law 85$857, \S 1$, September 2, 1958, 72 Stat. 1105, 38 USC $\$ 101$ (1958).
} 
worker effect, the phenomenon whereby employed workers have lower mortality than the general population. ${ }^{10}$ The HSE likely occurs, in part, because only the healthiest individuals join the military and in part because early-life physical training and health maintenance requirements for active-duty military service members combine to reduce mortality risks throughout middle age and later life. The protective effects of military service on disease mortality have been estimated to last from 10 to 30 years after military service has ended ${ }^{11}$ but most notably in reduced deaths due to CVD. ${ }^{9,12-14}$

Despite a reduction in mortality related to CVD, research indicates that veterans experience higher rates of CVD, are more likely to suffer from mental health problems and substance use disorders, and are more likely to have musculoskeletal disorders than nonveterans. ${ }^{15-18}$ Veterans are more likely to engage in risky health behaviors associated with CVD, such as alcohol and tobacco use and abuse. A longitudinal study indicates that veterans across ages are more likely to develop cardiovascular conditions over the course of a 20-year period than nonveterans, even when controlling for sociodemographic and other factors. ${ }^{19}$

Past research on the cardiovascular health of Veterans has largely taken place among veterans enrolled in the Veterans Administration (VA) health care system. ${ }^{20,21}$ This can be problematic because VA data tend to capture veterans who are in poorer health ${ }^{22}$ and who are more likely to report significant serviceconnected disability than non-VA-enrolled veterans. ${ }^{23,24}$ Second, VA-enrolled veterans are older than non-VA-enrolled veterans, with veterans over the age of 75 more likely to enroll in, and use, VA services than younger veterans. These older veterans are also more likely to have chronic health conditions in need of ongoing care. ${ }^{25}$ Third, most veterans are not enrolled in VA health care services. ${ }^{26}$ Recent estimates suggest that roughly $40 \%$ of eligible military veterans accessed and used VA services. ${ }^{25,27}$ The use of VAonly data might provide an incomplete picture of veteran cardiovascular morbidity, therefore, making it important to look to data sources that can capture a wider veteran population.

The purpose of this study was to examine the prevalence of CVD in a national sample of veterans and nonveterans with specific attention paid to individuals reporting CVD across ages. Specific attention was given to how veterans and nonveterans differ in their reports of specific cardiovascular is- sues (hypertension, heart problems, heart attack, coronary heart disease, and stroke) and the number of comorbid cardiovascular conditions by age.

\section{Methods}

The NHIS is a publicly available, nationally representative health survey of noninstitutionalized individuals living in the United States. The NHIS is conducted by the Centers for Disease Control and Prevention's National Center for Health Statistics (NCHS). ${ }^{28}$ The total household response rate for the survey was $75.7 \% .{ }^{29}$ The last 4 available years of the NHIS were pooled $(2012,2013,2014$, and 2015) to form 1 dataset. The analytic sample included 153,556 respondents that answered questions about veteran status, NHIS-designated cardiovascular conditions, and sociodemographic characteristics, including age, sex, race/ethnicity, education, marital status, and health status.

\section{Variables}

Veteran Status

The NHIS designates respondents who identified themselves as having ever served in the United States Armed Forces as "veterans." For the purposes of the present study, these respondents are referred to as having veteran status.

\section{Cardiovascular Health Conditions}

The NHIS questionnaire asks respondents whether they have "ever been told by their doctor that they had" 5 different cardiovascular conditions: hypertension, coronary heart disease, heart condition, stroke, and heart attack (myocardial infarction). The NHIS-designated categories are used for analyzing the cardiovascular conditions presented in this study. Each condition is examined individually, and to understand whether and how comorbid cardiovascular conditions differ by veteran status, an index, or count, was created. This index adds each of the 5 separate CVD conditions into a new variable that ranged from 0 to 5 , with 0 representing those with no cardiovascular conditions and 5 representing those reporting all 5 CVD conditions.

\section{Sociodemographic Characteristics}

Race and ethnicity was coded into 4 categories $^{2,30}$ : non-Hispanic white, non-Hispanic black/African

\footnotetext{
${ }^{2}$ Race and ethnicity (Hispanic origin of respondents) was collected by the NHIS following the guidelines set forth by
} 
American, non-Hispanic Asian and other race, and Hispanic/Latino. Sex was coded as $1=$ male and $0=$ female. Marital status was coded as $1=$ married/unmarried coresidential partners, $2=$ divorced/separated, $3=$ widowed, and $4=$ never married. Educational level was coded so that $1=$ less than a high school (HS) diploma, $2=\mathrm{HS}$ diploma, or general equivalency degree, $3=$ some college or 2 year college degree, $4=4$ year college degree, $5=$ graduate work or graduate degree. Age was coded in years with the exception of people over the age of $85^{3} \mathrm{~A}$ measure of self-rated health was included in this analysis; respondents rated their health as $5=$ excellent, $4=$ very good, $3=$ good, 2 = fair, or 1 = poor.

\section{Analytic Strategy}

To understand how veterans differ from nonveterans across cardiovascular conditions, analyses were conducted in 3 stages. First, bivariate analyses $(t$ test and $\chi^{2}$ tests) explored how veteran status varied by cardiovascular conditions and sociodemographic characteristics. Second, 5 logistic regression analyses examined how veteran status predicts the odds of having each of the reported cardiovascular conditions. Finally, a negative binomial regression analysis examined how veteran status predicts the odds of reporting multiple comorbid cardiovascular conditions. A negative binomial regression analysis was used because the indices of multiple cardiovascular conditions were discrete counts following a Poisson distribution with evidence of overdispersion (conditional variances were larger than the means) in the data. All analyses were weighted to account for the complex survey design of the NHIS survey instrument according to NHIS instructions.

\section{Results}

Table 1 displays the results of the bivariate analyses that indicate that veterans differ from nonveterans across heart conditions and other sociodemographic characteristics. Hypertension was the most

the Office of Management and Budget Directive 1530 . $\mathrm{OMB}$, Budget OoMa. Revisions to the Standards for the Classification of Federal Data on Race and Ethnicity. In: Register F, editor. 1997. p. 58782-90, 31. NCHS National Center for Health Statistics. Public Use Data File and Documentation. 2013.

${ }^{3}$ In the NHIS data, age is top coded so that the public release data does not identify individuals above the age of 85 years. common cardiovascular condition affecting 33.8\% of respondents. Almost $43 \%$ of veterans reported hypertension compared with $32.8 \%$ of nonveterans. Similar patterns were found in coronary heart disease affecting $9.9 \%$ of veterans and $5.5 \%$ of nonveterans. Other heart conditions were reported by $11.4 \%$ of veterans and $8.3 \%$ of nonveterans. Veterans also reported more stroke $(5.3 \%$ compared with $3.5 \%)$ and heart attacks $(7.8 \%$ compared with $4.1 \%$ ) than nonveterans. For comorbid heart conditions, nearly $50 \%$ of veterans reported at least 1 heart condition compared with $39 \%$ of nonveterans.

Veterans also differed from nonveterans across all sociodemographic characteristics. Military veterans tended to be non-Hispanic white $(76.7 \%$ compared with $61.2 \%)$ and male $(66.4 \%$ compared with $42.2 \%$ ) compared with nonveterans. Fewer veterans had never married (16\%) compared with nonveterans $(23.3 \%)$; said another way, veterans were more likely to have been married. Veterans also had higher levels of education, with $34.9 \%$ having a high school diploma or less compared with $41.4 \%$ of nonveterans. Veterans in the sample were also significantly older (56.2 years) than nonveterans (48.9 years).

The next step was to understand the difference in odds of having a cardiovascular condition when controlling for the differences highlighted in the section above. This is particularly important because the veterans in this sample tend to be older and male, both of which are unique risk factors for CVD. At the same time, veterans are more educated, more likely to be married, and more likely to be white, all known to be protective against cardiovascular conditions. These factors served as controls when further exploring whether veteran status has an independent effect on the odds of having a particular cardiovascular condition. Table 2 displays the results of 5 different multivariate logistic regression models testing the association between veteran status and reporting CVD conditions. Each odds ratio (OR) and 95\% confidence interval (CI) displayed in the table represent a separate regression model fully adjusted for sociodemographic factors.

Table 2 indicates that veterans have an odds of reporting hypertension that are $65 \%$ higher than the odds of nonveterans reporting hypertension, controlling for sociodemographic characteristics. Similarly, veterans are 76\% (OR, 1.76) more likely 
Table 1. Bivariate Analyses by Veteran Status

\begin{tabular}{|c|c|c|c|c|}
\hline Condition & $\begin{array}{l}\text { Total \%/Mean, } \\
\mathrm{n}=153,556\end{array}$ & $\begin{array}{l}\text { Veteran, \%/Mean, } \\
\quad \mathrm{n}=15,361\end{array}$ & $\begin{array}{c}\text { Nonveteran, \%/Mean, } \\
\mathrm{n}=138,195\end{array}$ & $\begin{array}{l}\text { Veteran vs } \\
\text { Nonveteran }\end{array}$ \\
\hline \multicolumn{5}{|l|}{ Cardiovascular condition } \\
\hline Hypertension & 33.8 & 42.8 & 32.8 & ** \\
\hline Coronary heart disease & 5.5 & 9.9 & 5.0 & ** \\
\hline Heart condition & 8.3 & 11.4 & 7.9 & ** \\
\hline Stroke & 3.5 & 5.3 & 3.3 & ** \\
\hline Heart attack & 4.1 & 7.8 & 3.7 & ** \\
\hline \multicolumn{5}{|l|}{ No. of heart conditions } \\
\hline 0 & 61.17 & 50.29 & 62.37 & ** \\
\hline 1 & 28.11 & 32.21 & 27.65 & \\
\hline 2 & 6.59 & 10.17 & 6.19 & \\
\hline 3 & 2.91 & 5.08 & 2.67 & \\
\hline 4 & 1.03 & 1.92 & 0.93 & \\
\hline 5 & 0.20 & 0.33 & 0.18 & \\
\hline \multicolumn{5}{|l|}{ General health } \\
\hline Excellent & 3.4 & 4.5 & 3.2 & ** \\
\hline Very good & 11.1 & 13.4 & 10.8 & \\
\hline Good & 27.4 & 31.0 & 27.0 & \\
\hline Fair & 31.5 & 30.7 & 31.5 & \\
\hline Poor & 26.8 & 20.3 & 27.5 & \\
\hline \multicolumn{5}{|l|}{ Race/Ethnicity } \\
\hline Non-Hispanic white & 61.2 & 76.7 & 59.5 & ** \\
\hline Non-Hispanic black & 13.8 & 13.3 & 13.8 & \\
\hline Non-Hispanic other race & 17.7 & 6.4 & 18.9 & \\
\hline Hispanic/latino & 7.4 & 3.5 & 7.8 & \\
\hline \multicolumn{5}{|l|}{ Marital status } \\
\hline Married/living with partner & 51.1 & 53.6 & 50.9 & ** \\
\hline Divorced/separated & 9.4 & 10.9 & 9.3 & \\
\hline Widowed & 16.9 & 19.5 & 16.6 & \\
\hline Never married & 22.5 & 16.0 & 23.3 & \\
\hline \multicolumn{5}{|l|}{ Educational level } \\
\hline Less than high school diploma & 15.1 & 7.3 & 15.9 & ** \\
\hline High school diploma or equivalent & 26.1 & 27.6 & 25.9 & \\
\hline Some college/2-year degree & 30.3 & 37.4 & 29.5 & \\
\hline Four year college degree or higher & 28.6 & 27.8 & 28.7 & \\
\hline \multicolumn{5}{|l|}{ Sex } \\
\hline Male & 44.6 & 66.4 & 42.2 & ** \\
\hline Female & 55.4 & 33.6 & 57.8 & \\
\hline Age (in years) & 49.6 & 56.2 & 48.9 & $* *$ \\
\hline
\end{tabular}

${ }^{* *} P<.01$.

to report a diagnosis of coronary heart disease and $125 \%$ more likely to report having had a heart attack (OR, 2.25). Veterans and nonveterans had similar rates of reporting "other heart problems" and stroke, controlling for all factors.

Next, a negative binomial regression model was used to understand whether veterans have higher counts of CVD. Table 3 displays the results of this analysis controlling for all sociodemographic char- acteristics. An interaction term for veteran status by age was included in these models. The purpose of the interaction term was to understand whether the relationship between the count of cardiovascular veteran status and age has a different trajectory based on veteran status, controlling for other sociodemographic factors.

In the negative binomial regression analysis, an incidence rate ratio (IRR) was calculated. An IRR is 
Table 2. Odds Ratios for Veterans Compared to Nonveterans Adjusting for Sociodemographic Characteristics*

\begin{tabular}{lcc}
\hline Condition & Odds Ratio & $\begin{array}{c}95 \% \text { Confidence } \\
\text { Interval }\end{array}$ \\
\hline Hypertension & 1.65 & $1.39-1.97$ \\
Coronary Heart Disease & 1.76 & $1.16-2.67$ \\
Heart Problems & 0.76 & $0.54-1.06$ \\
Stroke & 1.54 & $0.90-2.62$ \\
Heart Attack & 2.52 & $1.63-3.90$ \\
\hline
\end{tabular}

*Model includes marital status, sex, race/ethnicity, age, educational status, and general health.

interpreted to be the odds of having a higher incidence (number) of cardiovascular conditions. Table 3 shows that veteran status is associated with a $42 \%$ higher odds of having a higher number of cardiovascular conditions than nonveterans, controlling for sociodemographic characteristics. The interaction term "veteran status*age" in the model was a significant predictor of the count of cardiovascular conditions. This means that veteran status moderates the relationship between age and cardiovascular conditions (IRR, 0.99; 95\% CI, 0.99-0.99). The CI seems to be the same because of rounding to 2 decimal places in the tables. Next, the predicted count of cardiovascular conditions (using the STATA margins command) for veterans and nonveterans by age was calculated controlling for all the other factors in the model. Figure 1 displays this relationship.

Each dot (dark gray for veterans and light gray for nonveterans) represents the predicted count of cardiovascular conditions. Recall that an index variable for "cardiovascular conditions" was created to be the sum of all 5 cardiovascular conditions identified in the study. The index ranges from 0 (no conditions) to 5 (all cardiovascular conditions), and the predicted probability (obtained from the margins command in Stata) represents the predicted count of cardiovascular conditions. Predicted counts of cardiovascular conditions were calculated for veterans and nonveterans ages 35 through $85+$ and are presented in Figure 1. For a veteran at age 35 , the predicted count of cardiovascular conditions is 0.26 and the predicted count for nonveterans is slightly lower at 0.22 . Although these differences are small, they are statistically significant $(P<.01)$. Veterans continue to have higher predicted counts of cardiovascular conditions until
Table 3. Negative Binomial Regression for Cardiovascular Conditions by Veteran Status and Sociodemographic Characteristics

\begin{tabular}{|c|c|c|c|}
\hline Parameter & $\begin{array}{l}\text { Incidence Rate } \\
\text { Ratio }\end{array}$ & $95 \% \mathrm{CI}$ & \\
\hline \multicolumn{4}{|l|}{ Veteran Status } \\
\hline Veteran & 1.42 & $1.27-1.59$ & * \\
\hline \multicolumn{4}{|l|}{ Nonveteran } \\
\hline \multicolumn{4}{|l|}{ General Health } \\
\hline Excellent & 0.49 & $0.47-0.52$ & * \\
\hline Very good & 0.57 & $0.55-0.60$ & * \\
\hline Good & 0.66 & $0.63-0.70$ & * \\
\hline Fair & 0.83 & $0.79-0.87$ & * \\
\hline \multicolumn{4}{|l|}{ Poor } \\
\hline \multicolumn{4}{|l|}{ Race/ethnicity } \\
\hline \multicolumn{4}{|l|}{ Non-Hispanic white } \\
\hline Non-Hispanic black & 1.06 & $1.03-1.09$ & * \\
\hline Non-Hispanic other race & 0.92 & $0.90-0.95$ & * \\
\hline Hispanic/latino & 0.93 & $0.89-0.96$ & * \\
\hline \multicolumn{4}{|l|}{ Marital status } \\
\hline \multicolumn{4}{|l|}{$\begin{array}{l}\text { Married/living with } \\
\text { partner }\end{array}$} \\
\hline Widowed & 0.94 & $0.90-0.98$ & * \\
\hline Divorced/separated & 1.17 & $1.14-1.21$ & * \\
\hline Never married & 1.00 & $0.96-1.05$ & \\
\hline \multicolumn{4}{|l|}{ Educational level } \\
\hline \multicolumn{4}{|l|}{$\begin{array}{l}\text { Less than high school } \\
\text { diploma }\end{array}$} \\
\hline $\begin{array}{l}\text { High school diploma or } \\
\text { equivalent }\end{array}$ & 1.01 & $0.99-1.04$ & \\
\hline $\begin{array}{l}\text { Some college/2-year } \\
\text { degree }\end{array}$ & 1.06 & $1.03-1.09$ & * \\
\hline $\begin{array}{l}\text { Four year college degree } \\
\text { or higher }\end{array}$ & 1.00 & $0.97-1.03$ & \\
\hline \multicolumn{4}{|l|}{ Sex } \\
\hline Male & 1.22 & $1.19-1.26$ & * \\
\hline \multicolumn{4}{|l|}{ Female } \\
\hline Age (in years) & 1.04 & $1.04-1.04$ & * \\
\hline Age * veteran status & 0.99 & $0.99-0.99$ & * \\
\hline Constant & 0.07 & $0.07-0.08$ & \\
\hline Alpha parameter & 0.01 & $0.00-0.07$ & \\
\hline Log of alpha parameter & -4.64 & -6.58 to -2.70 & \\
\hline
\end{tabular}

${ }^{*} P<.01$.

CI, confidence interval.

about age 70 where the counts are the same, 0.94 for Veterans and 0.95 for nonveterans. After age 70 , nonveterans have higher counts of cardiovascular conditions and at ages 85 and older; the predicted count for veterans is 1.63 conditions and 1.76 for nonveterans. In other words, after age 70 , nonveterans are more likely to report higher CVD counts. 
Figure 1. Predicted Count of Heart Conditions by Veteran Status and Age.

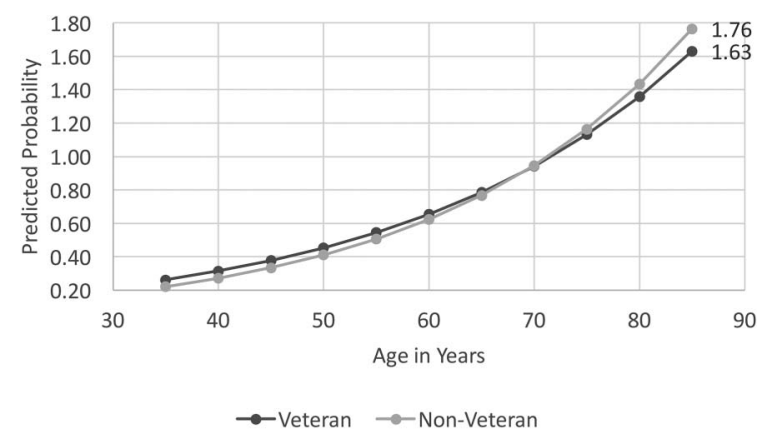

\section{Discussion}

Data from the NHIS were used to examine how a national sample of veterans and nonveterans differed by CVD condition, the number of comorbid CVD conditions, and whether, and how, veterans and nonveterans differed in their CVD count by age. Findings indicate an emerging health crisis for younger veterans, as their rate of CVD morbidity and comorbidity is higher than in same-aged nonveteran civilians. Starting at age 35, Veterans have a greater likelihood of reporting a greater number of cardiovascular conditions. Around age 70, there is a change in reporting, whereby nonveterans are more likely to report a greater number of cardiovascular conditions. Higher rates of CVD with a greater likelihood of CVD comorbidity at younger ages is a recipe for early on-set CVD mortality later in life, ${ }^{31}$ which may help explain this switch-over effect. Said another way, there may be fewer older Veterans reporting CVD conditions because they have not survived into older ages.

These findings support an emerging literature that questions whether the HSE is as relevant for the newest generation of veterans as it once was. ${ }^{2,32,33}$ Researchers from the VA note that "the healthy solider/worker effect gradually subdued over time. ${ }^{\prime 3}$ VA data estimate that male and female veterans have fewer expected life years $(0.8$ and 1.2 years, respectively) than nonveterans. ${ }^{4,33}$ This is concerning, because, as a group, veterans have greater access to health care, are more edu-

\footnotetext{
${ }^{4}$ The authors of the NSVAS report on Veteran life expectancy and mortality note that the higher mortality rate estimates for Veterans is incomplete because it is missing older and healthier Veterans. Data quality issues are noted above, but it is worth remembering that only about 40 percent of eligible Veterans are enrolled in VA healthcare.
}

cated, and they tend to earn higher wages than the nonveteran civilian population. ${ }^{34,35}$ Despite greater access to these health protective resources, those holding veteran status seem to have overall poorer cardiovascular health, and at younger ages, than their nonveteran counterparts.

Previous studies have explored combat exposure and long-term cardiovascular health but often neglect other explanatory factors for differences in CVD outcomes, such as preservice pre-existing mental health conditions or low socioeconomic status. ${ }^{36}$ Another potential explanation is found in how military service varies by era and conflict. ${ }^{37}$ Veteran cohorts experience different social and economic conditions that play a role in their longterm health. ${ }^{8}$ Recent, younger veterans are more likely than older veterans to have had lower grades in high school at the time of enlistment, come from single-parent households, and have parents with lower educational achievement, ${ }^{38}$ which are all predictors of persistent poverty over the life course, and all related to overall poorer cardiovascular health.

The NHIS does not ask about combat exposures, but the available evidence suggests that the recent wars in Iraq and Afghanistan have been more psychologically stressful than wars of other eras. This is due to a lack of clearly designated front lines and clear demarcation between enemy combatants and the civilians populations in which the enemy tended to embed; the higher number of war-zone tours; and longer deployments than earlier wars. ${ }^{39}$ In addition, the wars in Iraq and Afghanistan relied more heavily on service members from National Guard and Reserve units that, in general, have a lower state of military preparedness $^{32}$ and less access to military institutional support mechanisms such as Family Readiness Groups that provide crucial social, economic, and emotional support before, during, and after deployment. ${ }^{40}$ Emerging evidence suggests increased risks to health for Iraq and Afghanistan veterans who seem to have higher rates of tobacco and alcohol use, ${ }^{32,41,42}$ known risk factors for CVD, and to early onset mortality. Interestingly, the effects of tobacco and alcohol use seem to marginally affect the likelihood of veterans reporting higher rates of CVD conditions than nonveterans when controlling for age; this has been documented elsewhere. ${ }^{43}$ 


\section{Limitations}

There are several limitations to this study. Selfreports of the presence of a diagnosis of CVD conditions was explored. Individuals may not report specific conditions accurately or may under or over report certain diagnoses. That said, the NHIS is among the best available data for monitoring chronic disease among veterans living in the general American population. Another limitation is that data are cross-sectional and that only allows for an examination of veterans and nonveterans at a single time point. It is impossible to examine individuals across time. Therefore, understanding the development of CVD or the propensity of death from CVD and the difference between veterans and nonveterans remains out of reach when using NHIS data. Therefore, it is only possible to speculate on how higher CVD morbidity and comorbidity in younger veterans may indicate risks for later-life early CVD mortality.

Another distinct limitation is the possibility for "lead time" bias to skew results. Because veterans tend to have greater access to health care, there is also an increased chance that interaction with health care providers will result in receiving a CVD diagnosis and at earlier ages. The current analysis did not control for time-since-diagnosis, as this data are not available.

Despite these limitations, the findings of this study are consistent with research that demonstrates a link between military service and cardiovascular health. ${ }^{44}$ This study provides support for emerging research documenting the erosion of the HSE. ${ }^{32,43}$ When the data are taken together, this study provides more evidence of a looming cardiovascular health crisis for American veterans, who seem to have CVD at younger ages and at higher rates than nonveterans.

Future research should continue to explore the potential erosion of the $\mathrm{HSE}^{32}$ by examining other cardiovascular health correlates, such as risk-taking behavior, substance use and abuse, alcohol use, smoking, obesity, and exercise regimes. Spiro et al. 2016 (p. 7) ${ }^{8}$ argue that "Rather than asking whether military service has longterm health effects, the more appropriate questions are, for whom does military service have long- term positive and/or negative effects, in which domains, and why?" The research presented here moves us closer to answering these important questions.
To see this article online, please go to: bttp://jabfm.org/content/ 32/1/50.full.

\section{References}

1. Mozaffarian D, Benjamin EJ, Go AS, et al. Heart disease and stroke statistics-2015 update: a report from the American Heart Association. Circulation 2015;131:329-e2.

2. Hoerster K, Lehavot K, Simpson T, McFall M, Reiber G, Nelson K. Health and health behavior differences: US military, veteran, and civilian men. Am J Prev Med 2012;43:483-9.

3. National Center for Veterans Analysis and Statistics. VETPOP 2014: living veterans by period of service, gender, 2013-2014. Washington (DC): National Center for Veterans Analysis and Statistics; 2016.

4. Department of Defense. 2012 Demographics: profile of the military community. Washington (DC): Office of the Deputy Assistant Secretary of Defense; 2015.

5. Veterans' Benefits. Public Law $85-857, \$ 1$, September 2, 1958, 72 Stat. 1105, 38 USC $\$ 101$ (1958).

6. MacLean A, Elder GH. Military service in the life course. Ann Rev Sociol 2007;33:175.

7. Settersten RA. When nations call: how wartime military service matters for the life course and aging. Res Aging 2006;28:12-36.

8. Spiro AI, Settersten RA, Aldwin CM. Long-term outcomes of military service in aging and the life course: a positive re-envisioning. Gerontologist, 2016;56:5-13.

9. McLaughlin R, Nielsen L, Waller M. An evaluation of the effect of military service on mortality: quantifying the healthy soldier effect. Ann Epidemiol 2008;18:928-36.

10. Li CY, Sung FC. A review of the healthy worker effect in occupational epidemiology. Occup Med 1999;49:225-9.

11. Waller M, McGuire AC. Changes over time in the 'healthy soldier effect'. Popul Health Metr 2011;9: 1-9.

12. Kang HK, Bullman TA. Mortality among U.S. veterans of the Persian Gulf War. N Engl J Med 1996; 335:1498-504.

13. Seltzer C, Jablon S. Effects of selection on mortality. Am J Epidemiol 1974;100:367-72.

14. Kang HK, Bullman TA, MacFarland G, Gray G. Mortality among US and UK veterans of the Persian Gulf War: a review. Occup Environ Med 2002;59: 794-9.

15. Hinojosa R, Hinojosa MS. Activity-limiting musculoskeletal conditions in US veterans compared to non-veterans: results from the 2013 National Health Interview Survey. PLoS One. 2016;11:e0167143.

16. Sharafkhaneh A, Richardson P, Hirshkowitz M. Sleep apnea in a high risk population: a study of 
Veterans Health Administration beneficiaries. Sleep Med 2004;5:345-50.

17. Pizarro J, Silver R, Prause J. Physical and mental health costs of traumatic war experiences among Civil War veterans. Arch Gen Psychiatry 2006;63:194-200.

18. Stocker RP, Cieply MA, Paul B, et al. Combatrelated blast exposure and traumatic brain injury influence glucose metabolism during REM sleep in military veterans. NeuroImage 2014;99:207-14.

19. Assari S. Veterans and risk of heart disease in the United States: a cohort with 20 years of follow up. Int J Prev Med 2014;5:703-9.

20. Fasoli D, Glickman M, Eisen S. Predisposing characteristics. Enabling resources and need as predictors of utilization and clinical outcomes for veterans receiving mental health services. Med Care 2010;48: 288-95.

21. Barber J, Bayer L, Pietrzak R, Sanders K. Assessment of rates of overweight and obesity and symptoms of posttraumatic stress disorder and depression in a sample of Operation Enduring Freedom/Operation Iraqi Freedom veterans. Mil Med 2011;176:151-5.

22. Agha Z, Lofgren R, Van Rusiwyk J, Layde P. Are patients at Veterans Affairs Medical Centers sicker? A comparative analysis of health status and medical resource use. Arch Intern Med 2000;160:3252-7.

23. Department of Veterans Affairs. National survey of veterans, active duty service members, demobilized national guard and reserve members, family members, and surviving spouses: final report. Washington (DC): Department of Veterans Affairs; 2010.

24. Department of Veterans Affairs. Part 4-Schedule for Rating Disabilities. Washington (DC): Department of Veterans Affairs; 1976.

25. National Center for Veterans Analysis and Statistics. Unique veteran user report FY. 2012. Washington (DC): National Center for Veterans Analysis and Statistics; 2014.

26. Clever M, Segal D. The demographics of military children and families. Future Child 2013;23:13-39.

27. Bagalman E. The number of veterans that use VA Health Care Services: a Fact sheet. Congressional Research Service, Service CR; 2014. Contract No.: R43579.

28. Centers for Disease Control and Prevention. National Health Interview Survey fact sheet. Atlanta (GA): Centers for Disease Control and Prevention; 2015.

29. National Center for Health Statistics NHIS. Public use data file and documentation. Atlanta (GA): $\mathrm{Na}-$ tional Center for Health Statistics NHIS; 2013.

30. Executive Office of the President. Revisions to the standards for the classification of federal data on race and ethnicity. Washington (DC): Executive Office of the President; 1997.

31. Boscarino JA, Chang J. Electrocardiogram abnormalities among men with stress-related psychiatric disorders: implications for coronary heart disease and clinical research. Ann Behav Med 1999;21: $227-34$.

32. Bollinger MJ, Schmidt S, Pugh JA, Parsons HM, Copeland LA, Pugh MJ. Erosion of the health soldier effect in veterans of US military service in Iraq and Afghanistan. Popul Health Metr 2015;13:1-12.

33. National Center for Veterans Analysis and Statistics. Mortality rates and life expectancy of veterans: from 1980 to 2014, and by education and income. Washington (DC): Department of Veterans Affairs; 2017.

34. United States Department of Veterans Affairs. Profile of post-9/11 Veterans: 2014. Washington, DC: United States Department of Veterans Affairs; 2016.

35. Bureau of Labor Statistics. Employment situation of veterans summary Table A. Employment status of the civilian noninstitutional population 18 years and over by veteran status, period of service, and sex, 2014-2015 annual averages. Washington (DC): Bureau of Labor Statistics; 2015.

36. Levy B, Sidel VW. Health effects of combat: a lifecourse perspective. Ann Rev Public Health 2009;30: $123-35$.

37. Spiro AI, Schnurr PP, Aldwin CM. A life-span perspective on the effects of military services. J Geriatr Psychiatry 1997;30:91-124.

38. Bachman JG, Segal DR, Freedman-Doan P, O'Malley PM. Who chooses military service? Correlates of propensity and enlistment in the US Armed Forces. Mil Psychol 2000;12:1-30.

39. Fox AB, Walker BE, Smith BN, King DW, King LA, Vogt D. Understanding how deployment experiences change over time: comparison of female and male OEF/OIF and Gulf War veterans. Psychol Trauma 2016;8:135-40.

40. Hinojosa R, Hinojosa MS, Shirer Hognas R. Problems with veteran-family communication during Operation Enduring Freedom/Operation Iraqi Freedom military deployment. Mil Med 2012;177: 191-7.

41. Japuntich S, Gregor K, Pineles SL, et al. Deployment stress, tobacco use, and postdeployment posttraumatic stress disorder: gender differences. Psychol Trauma 2016;8:123-6.

42. Hermes EDA, Wells TS, Smith B, et al. Smokeless tobacco use related to military deployment. cigarettes and mental health symptoms in a large, prospective cohort study among US service members. Addiction 2012;107:983-94.

43. Hinojosa R. Cardiovascular disease among united states military veterans: evidence of a waning healthy soldier effect using the National Health Interview Survey. Chronic Ill. 2018. [E-pub ahead of print].

44. Elder GJ. Linking combat and physical health: the legacy of World War II in men's lives. Am J Psychiatry 1997;154:330-6. 